\title{
Case of Laryngeal Atresia, Tracheal Agenesis, Tracheo-Esophageal Fistula, Double Outlet Right Ventricle and Persistent Left Superior Vena Cava
}

\section{Hesham Al-Saloos*}

Section of Pediatric Cardiology, Hamad Medical Corporation, Doha, Qatar

\begin{abstract}
Congenital high airway obstruction syndrome (CHAOS) includes laryngeal atresia and tracheal agenesis which are rare and potentially lethal conditions. We describe a newborn term infant with laryngeal atresia and tracheal agenesis with a distal tracheo-esophageal fistula (TEF). He also had a double outlet right ventricle (DORV) and a persistent left superior vena cava (LSVC). To our knowledge this is the first report of this association.
\end{abstract}

Keywords: Laryngeal atresia; Tracheal agenesis; High airway obstruction syndrome; Respiratory distress; Central cyanosis; Difficult intubation; Double outlet right ventricle

\section{Introduction}

Laryngeal atresia and tracheal agenesis were first described more than 100 years ago. They are potentially lethal conditions unless emergency measures are undertaken at birth to secure the airway. The exact pathogenesis of both conditions is unknown. Several mechanisms have been proposed, all of which suggest a fault during early embryological differentiation of the respiratory tract [1].

Typically infants with either laryngeal atresia or tracheal agenesis present at birth with severe respiratory distress, central cyanosis and an absent cry. It is impossible for infants with laryngeal atresia to have an audible cry, however those with tracheal agenesis may have a weak cry and this may help distinguish between the two conditions clinically.

The immediate management of the two conditions also differ slightly. Laryngeal atresia requires emergency tracheostomy whereas patients with tracheal agenesis ventilates via bag and face mask or oesophageal intubation as long as there is a TEF [2].

DORV is an abnormality of ventriculo-arterial connection whereby both the aorta and pulmonary artery arise predominantly or exclusively from the right ventricle.

\section{Case Report}

A $3.2 \mathrm{~kg}$ male infant was born at term with APGARS of 1, 5 and 6 at 1, 5 and 10 minutes respectively. An antenatal ultrasound showed DORV and polyhydramnios of unknown aetiology. Immediately after birth, he had no spontaneous breathing requiring intubation and ventilation.

Despite adequate ventilation, the child remained cyanosed, with profuse respiratory secretions. A postnatal echocardiogram and computed tomography (CT) scan confirmed the antenatal suspicion of DORV with a large ventricular septal defect (VSD) and a persistent LSVC draining to the coronary sinus. Both great vessels were rising exclusively from the right ventricle and the aorta was anterior and to the left of the pulmonary artery. The VSD was remote and not committed to the great vessels (type 3) (Figures 1 and 2).

After 24 hours, he was electively extubated, however rapidly developed respiratory distress, hypoxia and poor respiratory effort necessitated re-intubation which proved technically difficult. Urgent laryngoscopy and bronchoscopy revealed long segment atresia of the proximal trachea; a small tracheo-oesophageal fistula connected the oesophagus to the distal trachea. Retrospectively, he had laryngeal atresia type 1, tracheal agenesis with tracheo-esophageal fistula and the initial ventilation was achieved by inadvertent intubation of the oesophagus and via the tracheo-oesophageal fistula.

No chromosomal abnormalities were found. In order to confirm the extent of the tracheal agenesis he underwent a thoracic computed tomography scan, at which time he become hypoxic and bradycardic. Attempts at resuscitation were unsuccessful.

Autopsy examination showed laryngeal atresia with fusion of the cricoid cartilage and complete tracheal agenesis with a distal TEF. Cardiac examination confirmed the echocardiographic diagnosis.

\section{Discussion}

Laryngeal atresia is the rarest congenital anomaly of the airway. It was first described by Rossi in 1826 [3]

Embryologically, the larynx develops from the cranial end of the laryngo-tracheal tube and from the 4 th and 6 th branchial arches. The laryngeal lumen occludes temporary by rapidly proliferating laryngeal epithelium and then recanalizes by the 10th week of gestation to give rise to the laryngeal ventricles, vocal folds, and vestibular folds. Laryngeal atresia represents the most severe form of failed recanalization [4].

Neonates with laryngeal atresia usually presents at birth with severe respiratory distress, central cyanosis, strong respiratory effort, and an inability to have an audible cry. Emergency tracheostomy is required soon after delivery to avoid early neonatal death. In neonates with of a distal TEF adequate ventilation could be achieved via oesophageal intubation.

Three types of laryngeal atresia have been described.

Type 1: supraglottic and infraglottic atresia. No vocal cords.

*Corresponding author: Hesham Al-Saloos, Director of Cardiac Catheterization Laboratory, Department of Pediatrics, Hamad General Hospital, Doha, Qatar Tel: 00974-44394196; E-mail: halsaloos@hamad.qa

Received April 14, 2015; Accepted July 31, 2015; Published August 10, 2015

Citation: Al-Saloos H (2015) Case of Laryngeal Atresia, Tracheal Agenesis Tracheo-Esophageal Fistula, Double Outlet Right Ventricle and Persistent Left Superior Vena Cava. J Neonatal Biol 4: 186. doi:10.4172/2167-0897.1000186

Copyright: @ $2015 \mathrm{Al}$-Saloos H. This is an open-access article distributed under the terms of the Creative Commons Attribution License, which permits unrestricted use, distribution, and reproduction in any medium, provided the original author and source are credited. 


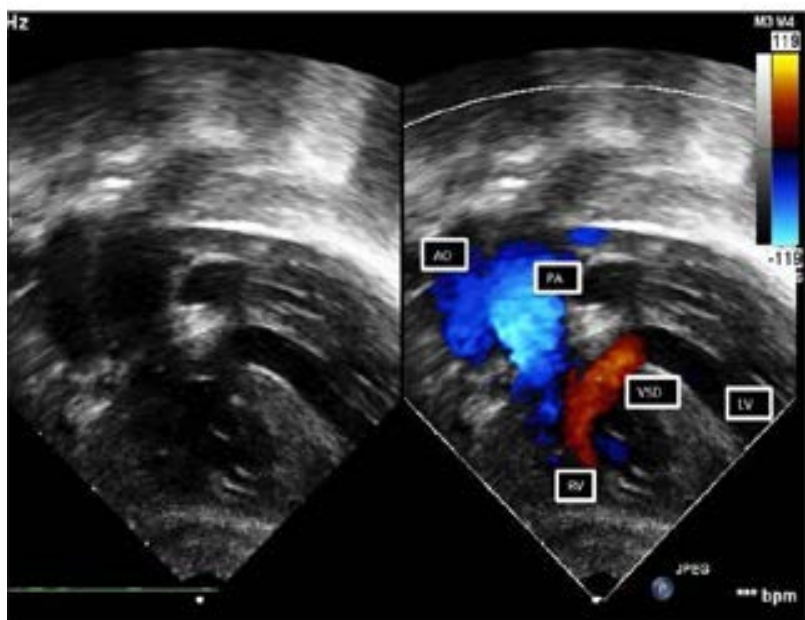

Figure 1: Echocardiogram of the heart.

Epigastric long axis view. 2D image on the left and 2D with colour doppler on the right. It is showing both great vessels are rising exclusively form the $\mathrm{RV}$ and the aorta is anterior and to the left to the pulmonary artery. Also, notice the VSD is not committed to the great vessels with left to right shunt. AO: aorta, PA: pulmonary artery, RA: right atrium, RV: right ventricle, LV: left ventricle, VSD: ventricular septal defect.
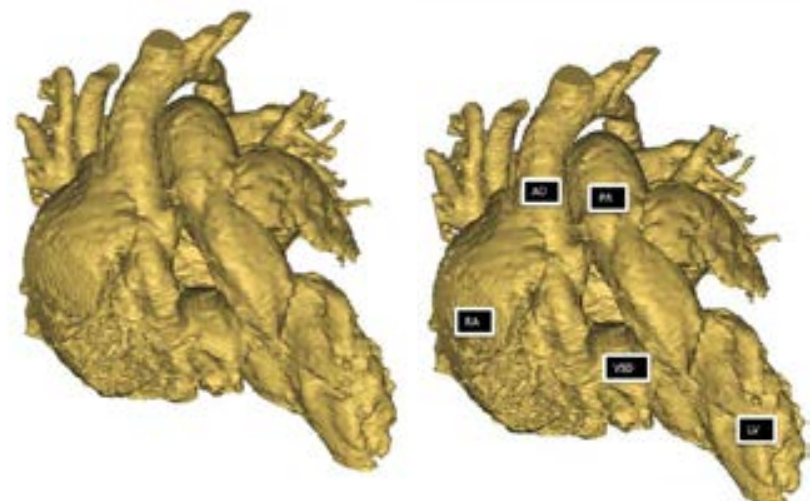

Figure 2: Cardiac CTA (Computed Tomography Angiography) with a $3 \mathrm{D}$ reconstruction of the heart. It is showing both great vessels are rising exclusively form the RV and the aorta is anterior and to the left to the pulmonary artery. AO: aorta, PA: pulmonary artery, RA: right atrium, LV: left ventricle, VSD: ventricular septal defect.

Type 2: infraglottic atresia: caused by a malformed cricoid cartilage. Vocal cords and arytenoids are normal.

Type 3: glottic atresia: caused by a membrane of fibrous connective tissue occluding the glottis [5].

The first documentation of tracheal agenesis was by Payne in 1900 [6]. Tracheal agenesis is defined as absence of the trachea from the cricoid cartilage proximally to the carina distally. It, too, has a high mortality. Floyd classified tracheal agenesis based on the degree of distal tracheobronchial development and its connections to the oesophagus. He described 3 types. Type 1: Short segment atresia of the proximal trachea, a normal distal trachea with normal bronchi and a tracheo-oesophageal fistula. Type 2: Long segment tracheal atresia with normal bronchi with or without a broncho-oesophageal fistula. Type 3: Complete tracheal atresia with bronchi arising directly from the oesophagus [7].
The oesophagus and trachea develop from the foregut. The published data on the exact course of their development is controversial [8].

Antenatal diagnosis of CHAOS (including laryngeal atresia and/ or tracheal agenesis) may be possible and should be suspected when hyperechogenic, enlarged lungs, a flattened or inverted diaphragm, post-obstruction dilatation of the airway, fetal hydrops, and polyhydramnios are seen on prenatal ultrasound [9].

Prenatal diagnosis pre-empts the need for ex utero intrapartum treatment (EXIT) procedure to secure the airway at birth. This requires a multidisciplinary team approach to maintain the feto-placental circulation after birth until the airway is evaluated and secured [10].

Other resuscitation options include immediate oesophageal intubation with positive pressure ventilation or urgent tracheostomy.

Postnatal diagnosis can be confirmed by bronchoscopy or cervical and thoracic computed tomography scan.

DORV was first reported by Abernathy in 1793. It is a relatively rare congenital cardiac lesion occurring in less than $1 \%$ of all patients with congenital heart disease. In this condition, both great arteries arise predominantly or exclusively from the right ventricle. The pathological classification of DORV is based on the relationship of the great arteries and the position of the VSD, the latter being an important determinant of the surgical options. The relationships of the great vessels are quite variable with 3 different possibilities. 1) The aorta is posterior and rightward of the pulmonary artery; the most common relationship. 2) Side-by-side great vessels with the Aorta to the right of the pulmonary artery. 3) The aorta is anterior and leftward of the pulmonary artery; the rarest relationship.

Four types of VSD's are described with DORV 1) Subaortic: the VSD is below the aortic valve, 2) Subpulmonary: the VSD is below the pulmonary valve, 3) Non-committed: The VSD is located away from both semilunar valves and 4) Doubly committed: the VSD is large and closely related to both semilunar valves. The classification of DORV can be complex as each type of arterial relationship can exist with any of the $4 \mathrm{VSD}$ positions [11].

Obler reviewed 149 reported cases of DORV and characterized associated anomalies. Chromosomal abnormalities were present in 61 patients (41\%) the most common of which were trisomy 13 and 18 , and 22q11 microdeletion. 84 patients (56\%) had non chromosomal abnormalities [12].

The presentation of patients with DORV is variable and dependant on the complexity of the malformation. It can present with central cyanosis if associated with pulmonary atresia, a sub-pulmonary VSD with pulmonary stenosis or less commonly tricuspid atresia [11].

Persistent LSVC to coronary sinus is present in up to $9 \%$ of people with congenital heart disease. Although in itself it is of no haemodynamic significance, it remains important to identify prior to cardiac surgery [13].

\section{Conclusion}

Laryngeal atresia and tracheal agenesis are rare congenital abnormalities which collectively fall into the category of CHAOS. They should be suspected in new-borns presenting with immediate respiratory distress, strong respiratory effort, absence of a cry and the inability to move air in and out of the thorax. The described case highlights 3 important aspects with regards to laryngeal atresia and tracheal agenesis. First, antenatal diagnosis may be possible which 
Citation: Al-Saloos H (2015) Case of Laryngeal Atresia, Tracheal Agenesis, Tracheo-Esophageal Fistula, Double Outlet Right Ventricle and Persistent Left Superior Vena Cava. J Neonatal Biol 4: 186. doi:10.4172/2167-0897.1000186

Pge 3 of 3

can aid the clinician to plan for EXIT procedure or other immediate postnatal management.

Second, immediate oesophageal intubation and positive pressure ventilation can be lifesaving as many infants have an associated distal tracheo-esophageal fistula through which they can be temporarily ventilated, and thirdly infants who are adequately ventilated and remain cyanosed may have associated cyanotic congenital cardiac lesions which should be actively sought and excluded.

\section{References}

1. Harrison MR, Adzick NS, Flake AW, VanderWall KJ, Bealer JF, et al. (1996) Correction of congenital diaphragmatic hernia in utero VIII: Response of the hypoplastic lung to tracheal occlusion. J Pediatr Surg 31: 1339-1348.

2. Saleeby MG, Vustar M, Algren J (2003) Tracheal agenesis: a rare disease with unique airway considerations. Anesth Analg 97: 50-52

3. Rossi $F$ (1824) De nonnullis monstruositatibus in internis humani corporis partibus. Mem R Accad Sci Torino 30: 155-157.

4. Hartnick CJ (2003) Syndromic and other congenital anomalies of the head and neck. Otolaryngologic Clinics of North America 33: 1293-1308.
5. Smith II, Bain Ad (1965) Congenital Atresia Of The Larynx. A report of nine cases. Ann Otol Rhinol Laryngol 74: 338-349.

6. Payne WA (1900) Congenital absence of the trachea. Brooklyn Medical Journa 14: $568-569$

7. Floyd J, Campbell Dc Jr, Dominy De (1962) Agenesis of the trachea. Am Rev Respir Dis 86: 557-560.

8. Kluth D, Fiegel H (2003) The embryology of the foregut. Semin Pediatr Surg 12: 3-9.

9. Onderoglu L, Saygan Karamürsel B, Bulun A, Kale G, Tunçbilek E (2003) Prenatal diagnosis of laryngeal atresia. Prenat Diagn 23: 277-280.

10. DeCou JM, Jones DC, Jacobs HD, Touloukian RJ (1998) Successful ex utero intrapartum treatment (EXIT) procedure for congenital high airway obstruction syndrome (CHAOS) owing to laryngeal atresia. J Pediatr Surg 33: 1563-1565.

11. Anderson R, Redington AN, Rigby ML, Wernovsky G (2010) Paediatric cardiology. (3rd edn) Churchill Livingstone, London.

12. Obler D, Juraszek AL, Smoot LB, Natowicz MR (2008) Double outlet right ventricle: aetiologies and associations. J Med Genet 45: 481-497.

13. Nsah EN, Moore GW, Hutchins GM (1991) Pathogenesis of persistent left superior vena cava with a coronary sinus connection. Pediatr Pathol 11: 261-269. 